\title{
Maternal sensitivity and mother-infant attachment are associated with antibiotic uptake in infancy
}

\author{
Marina Fuertes $^{\mathrm{a}, \mathrm{b}, 1}$, PhD, Joana L. Gonçalves ${ }^{\mathrm{a}}$, MS, Anabela Faria ${ }^{\mathrm{c}}$, PhD, Pedro Lopes-dos- \\ Santos $^{\mathrm{a}}, \mathrm{PhD}$, Inês C. Conceição ${ }^{\mathrm{d}}, \mathrm{MD}, \mathrm{PhD}, \&$ Francisco Dionisio $^{\mathrm{e}}{ }^{1}, \mathrm{PhD}$
}

\section{Affiliations:}

${ }^{\mathrm{a} C e n t r o}$ de Psicologia, University of Porto, Portugal.

${ }^{\text {b} E s c o l a ~ S u p e r i o r ~ d e ~ E d u c a c ̧ a ̃ o ~ d e ~ L i s b o a, ~ P o r t u g a l . ~}$

${ }^{c}$ Hospital de Santo Espírito, Terceira, Azores, Portugal.

${ }^{\text {d} S e r v i c ̧ o ~ d e ~ P a t o l o g i a ~ C l i ́ n i c a, ~ H o s p i t a l ~ N o s s a ~ S e n h o r a ~ d o ~ R o s a ́ r i o, ~ B a r r e i r o, ~ P o r t u g a l . ~}$

${ }^{\mathrm{e}} \mathrm{cE} 3 \mathrm{c}$ - Centre for Ecology, Evolution and Environmental Changes, and Departamento de Biologia Vegetal, Faculdade de Ciências, Universidade de Lisboa

${ }^{1}$ Correspondence addresses:

Marina Fuertes, PhD: Escola Superior de Educação de Lisboa, Campus de Benfica do IPL, 1549003 Lisboa, Portugal. Email: marinaf@eselx.ipl.pt

$\mathrm{Or}$

Francisco Dionisio, PhD: Departamento de Biologia Vegetal, Ed.2, Piso2, Faculdade de Ciências, Universidade de Lisboa, Campo Grande, 1749-016 Lisboa, Portugal. Email: dionisio@fc.ul.pt

\section{NUMBER OF TABLES: 3; NUMBER OF FIGURES: 0}

Supplementary file at the end of the Main document

The authors declare no conflicts of interest. There was no prior presentation of study data as an abstract or poster.

Funded by Ministry of Education and Science, Fundação para a Ciência e a Tecnologia (FCT), (PTDC/MHC-PED/1424/201 and PTDC/PSI-EDD/110682/2009 [both to MF])

ACKNOWLEDGMENTS: We gratefully acknowledge the families that participated in this study. We are also grateful to Prof. Dr. Humberto Machado, University of Porto, for calling our attention to the ISAAC study, Dr. J. N. Tendeiro and reviewers for the highly constructive comments that substantially ameliorated the manuscript.

AUTHOR CONTRIBUTIONS: conceptualization, formal analysis, and writing of original draft: MF and FD; funding acquisition: MF; investigation: MF, JG, AF; supervision and validation: MF and PLS; statistical analysis: MF, PLS, FD; review \& editing: all authors. 


\section{ABSTRACT}

Attachment security has been associated with health status and symptom reporting. In this

37 longitudinal study, we investigated the association between antibiotics uptake by infants at 9-

38 months and mother-infant attachment at 12-months. Logistic regression analyses indicated that

39 lower maternal sensitivity was associated with increased odds of antibiotic uptake. Furthermore,

$4089.7 \%$ of insecure-ambivalent infants consumed antibiotics, which contrasted with $32.5 \%$ of

41 avoidant infants and $21.5 \%$ of secure infants. This study suggests that maternal behavior and

42 mother-infant attachment impact on antibiotic consumption, which is worrying because

43 antibiotics may lead to several health problems later in life and antibiotic-resistance. 


\section{INTRODUCTION}

Symptom-reporting has been shown to affect the propensity of antibiotic prescription by general health practitioners (Sirota, Round, Samaranayaka, \& Kostopoulou, 2017). It is well documented that medical doctors are often under pressure to prescribe antibiotics, even when these drugs are unnecessary or unhelpful (for example, in the case of diseases caused by viruses). Several factors contributing to this problem have been identified, namely patients' lack of knowledge and concern (Altiner et al., 2007), underestimation of antibiotic resistance (Wood et al., 2013), and patients' coercion over medical doctors to prescribe antibiotics (Arroll, Kenealy, \& Kerse, 2003). Additionally, antibiotic prescription encourages patients to assume the use of antibiotic treatment in future episodes of illness (Little et al., 1997; for a review, see Martinez-Gonzalez et al., 2017). This has led to over-prescription of antibiotics in many countries, including European countries (Neumark, Brudin, \& Molstad, 2010; Tyrstrup et al., 2017), U.S.A. (Kronman, Zhou, \& Mangione-Smith, 2014), or Australia (Fletcher-Lartey, Yee, Gaarslev, \& Khan, 2016). Over-prescription contributes to an increase in antibiotic resistance (Friedman, Temkin, \& Carmeli, 2016). Moreover, in the long term, the uptake of antibiotics may negatively impact children's future development and health conditions. For example, a positive association has been found between antibiotic prescription during infants' first six months of life and the development of asthma and allergy when they are six years old (Risnes, Belanger, Murk, \& Bracken, 2011). Also, a positive association has been found between antibiotic prescription in the first six months of life and an increased probability of being overweight at seven years 
old among children whose mothers had an average healthy weight (Ajslev, Andersen, Gamborg, Sorensen, \& Jess, 2011). Furthermore, antibiotics uptake increases the susceptibility to pathogens and is related to several health conditions such as inflammatory bowel disease, rheumatoid arthritis, type 1 diabetes, and atopy (for a review, see Francino, 2016).

Health outcomes and quality of life have also been associated with mother-infant attachment (Andrews, Meredith, \& Strong, 2011; Feeney, 2000; P. J. Meredith \& Strong, 2019). Humans are born predisposed to become attached to caregivers during their first year of life (Bowlby, 1969). When children develop trust in the availability and reliability of their attachment figures, their anxiety is reduced, and they can operate in the world with confidence (Bowlby, 1969).

(1)

Because not all relationships offer a secure base, infants use different strategies to address their attachment needs. Ainsworth et al. (M. D. Ainsworth, Blehar, Waters, \& Wall, 1978) described infants' attachment organization in three attachment patterns: securely attached infants (named by Ainsworth as pattern B), avoidant infants (pattern A) and ambivalent infants (pattern C) (for a review, see Cassidy \& Shaver, 2018). Securely attached infants (B) generally display their emotional communication and intentions openly by signaling or seeking contact with caregivers when distressed. They are easily comforted and use their caregiver as a secure base for exploration. Conversely, insecurely attached infants ( $A$ and $C)$ do not rely on a secure base when distressed. Insecure-avoidant attached infants $(A)$ tend to avoid proximity with their caregivers by over-activating the exploratory system, while insecure-ambivalent 
attached infants $(\mathrm{C})$ are characterized by an ambivalent behavior, alternating between strong proximity seeking/contact maintenance and physical resistance to the contact with their attachment figures (DeWolff \& van ljzendoorn, 1997; Lucassen et al., 2011).

Parents of secure infants are highly sensitive, offering comfort and protection in alarming situations as is the case of infants' disease (M. D. S. Ainsworth, Bell, \& Stayton, 1974). Maternal sensitivity has been defined by attachment theorists as mother's: (1) ability to read and interpret infant's solicitations and distress signals; (2) ability to comfort the infant in stressful situations; (3) ability to respond in a sensitive, contingent, and prompt way; and (4) availability to socially engage in a warm, reciprocal and contingent manner (M. D. S. Ainsworth et al., 1974; Beeghly, Fuertes, Liu, Delonis, \& Tronick, 2011; Braungart-Rieker, Garwood, Powers, \& Wang, 2001; Mesman, Oster, \& Camras, 2012).

Attachment security has also been associated with health status, health visits, and symptom reporting (for a recent review, see P. J. Meredith \& Strong, 2019). Secure attachment predicts better health and developmental outcomes when compared with insecure mother-infant relationships (P. J. Meredith \& Strong, 2019) and seems to be associated with improved quality in the patient-doctor relationship (defined as patients' degree of trust and security evaluated in a self-reported measure) (ZaporowskaStachowiak, Stachowiak, \& Stachnik, 2019).

Inversely, an insecure attachment is more likely to be observed in children with chronic diseases (Cassibba, van ljzendoorn, Bruno, \& Coppola, 2004; P. J. Meredith \& 
111 Strong, 2019; Pietromonaco \& Powers, 2015; Simmons, Goldberg, Washington,

112 Fischerfay, \& Maclusky, 1995). In a longitudinal study, it was found that insecurely

113 attached infants had more somatic complaints at six years old (Lewis, Feiring,

114 Mcguffog, \& Jaskir, 1984).

115

116

117

118

119

120

121

122

123

124

125

126

127

128

129

130

131

However, insecure-avoidant and insecure-ambivalent individuals seem to adopt different responses to pain and sickness (McCallum \& McKim, 1999; P. Meredith, Ownsworth, \& Strong, 2008). Faced with the same symptoms, avoidant attached children and teenagers display higher levels of emotional control and lower levels of negativity compared with insecure-ambivalent individuals (Feeney, 2000). Furthermore, compared with secure attached, insecure-ambivalent individuals have higher symptomreporting and request more health visits (Andrews et al., 2011; Feeney, 2000).

Since attachment patterns are behavioral strategies activated to overcome stressful situations, they are especially elicited when infants feel pain, fatigue, or sickness (Bowlby, 1969). In response, attachment figures need to find appropriate health-care and means to alleviate the infant's pain.

It is well documented that ambivalently attached infants tend to exaggerate the display of their emotions and needs in ways that influence attachment figures' behavior (Cassidy \& Shaver, 2018). In the presence of any perceived danger (such as pain, hunger, fear, and others), these infants arouse their feelings of anxiety and despair to obtain responses from their attachment figures that can decrease the probability of imminent danger. This ambivalent pattern results from inconsistent, anxious, or absent 
caregiving (Beeghly et al., 2011; Cassidy \& Shaver, 2018). To obtain responses and attention from their caregivers, ambivalent-attached infants react with over-emotional angry and fear responses expressed by heavy crying, inability to self-soothe or strong motor reactions (Barbosa, Beeghly, Moreira, Tronick, \& Fuertes, 2018), alternating with behaviors of proximity seeking, contact and desire for comfort (M. D. S. Ainsworth et al., 1974; Bretherton, 1992). Therefore, we hypothesize that infants who exacerbate their emotions while feeling pain or physical illness (namely insecurely ambivalent attached infants) may raise exacerbated concerns to their parents and health professionals, eventually leading to antibiotic prescription.

However, other factors might contribute to antibiotics uptake, namely type of labor, breastfeeding, and enrollment in daycare. Regarding the type of labor, hundreds of bacterial species typically colonize human beings, and the infant intestinal colonization by microorganisms begins with oral inoculation by maternal vaginal microbiota (Houghteling \& Walker, 2015; Jakobsson et al., 2014). A vaginal birth ensures that infants' body is colonized by the correct founding microbial species at birth, protecting them from infectious and non-infectious diseases (Buffie \& Pamer, 2013; Rautava, 2016; Sassone-Corsi \& Raffatellu, 2015). Breastfeeding is also an important factor for infants' health. The presence of secretory immunoglobin IgA in breast milk is important for the recognition of microorganisms of maternal origin, contributing to the establishment of the intestinal microbiota (Rautava \& Walker, 2009). Moreover, many molecules present in breastmilk display antimicrobial activity as proteins $\kappa$-casein, $\alpha$ lactalbumin, lactoferrin, haptocorrin, or the lysozyme enzyme that destroys the cell wall 
154 of gram-negative bacteria (Rautava \& Walker, 2009). Therefore, breastfed children are 173 life. less susceptible to infectious diseases. The age of infants when entering daycare may also be relevant given that some studies have reported a higher rate of infections in this context when compared with children reared at home (Schuez-Havupalo, Toivonen, Karppinen, Kaljonen, \& Peltola, 2017).

To test the hypothesis that the prevalence of antibiotic uptake is higher in insecurely resistant attached infants compared with infants classified with other attachment patterns, we started by investigating the factors associated with infants' antibiotic consumption in the first nine months of life from a range of variables, including the type of labor (vaginal vs. non-vaginal), enrollment in daycare vs. reared at home, breastfeeding time-period (in months), quality of maternal interactive behavior (i.e., maternal sensitivity, maternal control, maternal unresponsivity), quality of infant's interactive behavior (i.e., infant's cooperative behavior, infant's compulsive behavior, infant's difficult behavior, infant's passive behavior), infants' clinical conditions at birth usually associated with increased health problems (gestational age at birth, gestational weight at birth, Apgar $1^{\text {st }}$ minute, Apgar $5^{\text {th }}$ minute), and socio-demographic variables, such as maternal age, maternal education, number of siblings, infant's gender. Moreover, we estimated the prevalence of infants' attachment pattern between those who consumed and those who did not consume antibiotics in the first nine months of 


\section{METHODS}

\section{Participants}

The original sample comprised 176 mother-infant dyads. To homogenize our sample, a total of 42 dyads were excluded based on six exclusion criteria (Suppl. Inf. Fig. S1). First, dyads with mothers with less than seven years of formal education were not included. Second, dyads with babies not breastfed for, at least, the first month postpartum were also excluded. Third, dyads with infants who had severe or chronic health problems (e.g., asthma, cardiopathies) or allergies, were also excluded. The reason for excluding these dyads is that these health conditions could lead to more medical visits, eventually increasing the probability of antibiotic prescription.

Additionally, infants with low birth and gestational age are more likely to present serious health and developmental conditions (for a review, see Fuertes et al., 2012). Therefore, we also excluded dyads with babies with low birth weight (BW) for their gestational age (GA) at birth (4th criterion); less than 32 weeks of GA (5th criterion); and less than 1500 $\mathrm{g}$ of BW (6th criterion). Ten of the excluded dyads presented more than one exclusion criterion.

The final sample comprised 134 mother-infant dyads, which included 57 girls and 77 boys and their respective mothers. The mean GA of the infants was 37.60 weeks $(S D=2.37$ weeks $)$ and an average BW of $2991.11 \mathrm{~g}(S D=622.09 \mathrm{~g})$. Ninety-seven infants were born full-term and healthy at delivery ( $\geq 37$ and $<42$ gestational weeks). The other 37 infants were healthy prematurely born ( $\geq 32$ and $<36$ gestational weeks). Infants were breastfed for an average of 3.91 months ( $S D=2.60$ months). Throughout 
197 the conduction of this study, all infants continued to be healthy (except for normal

198 infections and other occasional minor diseases) and had normal development until our

199 last observation at 12 months. Mothers were healthy at infants' birth and had no medical 200 history (i.e., a clinical record) of chronic diseases, mental health disorders, or substance

201 (alcohol/drug) abuse. Moreover, all mothers were married or living in cohabitation with

202 the infant's father. All families were from low to high middle-class backgrounds,

203 representing $75 \%$ of the Portuguese population (INE, 2011).

Measures

Medical History Interview. In this interview, a female research assistant queried mothers about how many times their infants were ill, and if antibiotics were used in the first nine months of life. All mothers had information regarding antibiotic prescription; however, only 97 mothers were able to describe how many times their infants were ill.

Maternal Sensitivity in Free Play Interaction. The quality of the mother-infant relationship, namely, maternal sensitivity was assessed during a 5-min unstructured mother-infant free-play interaction coded using the scale Child-Adult Relationship Experimental Index (CARE-Index) (Crittenden, 2003). According to the CARE-Index manual, maternal sensitivity is defined as any pattern of behavior that pleases the infant and increases the infant's comfort and attentiveness and reduces his/her distress and disengagement. The CARE-Index was used to score qualitative dimensions of infantadult interaction during free play at the 9-months lab visit. The CARE-Index system assesses seven aspects of mother-infant interactive behavior: facial expressions, verbal 
expressions, position and body contact, affection, turn-taking contingencies, control, and choice of activity. Each adult and infant are evaluated separately in each of these seven dimensions of interactive behavior. The points for each dimension are added to yield seven scale scores, three adult independent scales, namely, Sensitivity, Control, and Unresponsiveness, and four infant independent scales, namely, Cooperative, Compliant-compulsive, Difficult, and Passive, behaviors (Crittenden, 2003). CAREIndex was scored by two trained coders that were blind against the study hypothesis. Intercoder reliability was evaluated by comparing the two coders' ratings using intraclass correlation coefficients (ICC) (Cicchetti, 1994). The obtained overall average ICCs (.81) showed a substantial strength of concordance (Landis \& Koch, 1977).

Mother-Infant Attachment. At the 12-months visit, mother-infant dyads were videotaped during the Strange Situation (SS) (M. D. Ainsworth et al., 1978). SS is a 21-minute laboratory paradigm consisting of a sequence of eight episodes designed to place mild but increasing levels of stress on the infant (i.e., being introduced to an unfamiliar playroom, interacting with an unfamiliar adult stranger, and brief separations from and reunions with the mother). The videotapes of infants' attachment behavior during the SS were scored by two trained, reliable coders following the procedures developed by $M$. D. Ainsworth et al. (1978) and Main and Solomon (1990). Infants were classified as either securely attached (B), insecure-avoidant (A), and insecure-ambivalent (C). Cohen's kappa coefficient for attachment classifications among coders was .90 , corresponding to an excellent agreement (Landis \& Koch, 1977). 


\section{Procedures}

Mother-infant dyads were recruited after delivery at hospitals of Santo Espirito da Ilha Terceira (Azores), S. João (Oporto), and Pedro Hispano (Matosinhos). Recruitment was authorized by the three hospitals' administration boards based on favorable reports of their respective ethical committees. Pregnancies had been monitored according to recognized obstetrical standards and mothers did not have major medical complications associated with delivery.

This study was performed according to the guidelines presented in the Declaration of Helsinki, the American Psychology Association (APA) guidelines for research, and the EU General Data Protection Regulation (GDPR) - Regulation (EU) 2016/679. No risks of vulnerability/stigmatization of the participants resulting from this research were expected and the methods and proceedings selected are extensively used in Developmental Psychology research over the last decades, without risks reported. All procedures involving human subjects in this study and the original projects (PTDC/ PSIEDD/ 110682/ 2009; PTDC/ MHC-PED/ 1424/ 2014) were approved by the Ethics Committee of the Portuguese hospitals of Santo Espirito da Ilha Terceira (Azores), S. João (Oporto) and Pedro Hispano (Matosinhos), and the National Commission for Data Protection (2019/2017), and were developed in collaboration with the respective nursing and medical teams.

Under the protocols established with the Ethics Committees, potential participant mothers were contacted in the neonatal obstetric units within the first 48 hours after 
261 infants' birth. The study's purpose and procedures were then explained, and mothers 262 were asked about their willingness to participate and if so, informed consent was collected (signed by the parents). Those who had shown interest in participating were

264 administered a brief interview to collect demographic information. With the mothers' consent, data concerning infants' perinatal health status was abstracted from medical records. Demographic and health information was checked to determine eligibility. Procedures were followed to ensure the confidentiality of the data collected.

Mothers were recruited at the maternity ward (newborn's first $48 \mathrm{~h}$ of life period), and those who accepted to participate, were then re-contacted near the infants' age of 9 and 12 months to schedule the follow-up visits to the laboratory. At the 9-months visit, mothers described their infant health and development in the Medical History Interview and participated with their infant in the 5-min unstructured free play interaction. At the 12-month visit, dyads were videotaped in the Strange Situation (SS) paradigm (M. D. 274 Ainsworth et al., 1978).

\section{Data analyses} current study. First, we calculated the prevalence of antibiotic consumption until 9 months of life. Second, to study the factors associated with antibiotic uptake, we performed Student $t$-tests using the following variables: breastfeeding time-period, maternal sensitivity, maternal control, maternal unresponsivity, infant cooperative 281 behavior, infant compulsive behavior, infant difficult behavior, infant passive behavior, 
282 Apgar $1^{\text {st }}$ minute, Apgar $5^{\text {th }}$ minute, GA, GW, maternal age, maternal education, and 283 number of siblings. Third, Chi-Square tests were used to study the prevalence of 284 antibiotic uptake according to the type of labor, enrollment in daycare, and infant's 285 gender. Fourth, the factors significantly associated with antibiotic uptake in Student's $t$ 286 test were computed in a binary logistic regression (forward stepwise - Wald) to explore 287 the predictors of antibiotics consumption in the first 9-months of infants' life. Fifth, the 288 distribution of infants' attachment pattern was analyzed using univariate frequency 289 analysis. Sixth, a $\chi^{2}$-test was used to study the prevalence of antibiotic consumption 290 among patterns of attachment, followed by a z-post hoc analysis. Bonferroni correction 291 was used for adjusting $p$-values .

292 To carry out the mean difference tests, the assumptions of normality and 293 homogeneity of variances were tested. The significance level of $p<.05$ was assumed 294 for analyses.

\section{Data availability}




\section{RESULTS}

\section{Factors associated with antibiotics uptake}

At nine months of age, antibiotics had already been administered to $39.6 \%$ of infants in our sample. From a range of factors included in our analysis, only maternal sensitivity $(p=.008)$, infant cooperative behavior $(p=.014)$ and Apgar at $1^{\text {st }}(p=.020)$ and $5^{\text {th }}$ minute $(p=.013)$ were associated with antibiotic uptake (Table 1$)$. Maternal sensitivity and infant cooperative behavior were significantly higher in infants that did not consume antibiotics (Table 1). On the other hand, the mean Apgar, both at $1^{\text {st }}$ and $5^{\text {th }}$ minute, were significantly higher among infants who consumed antibiotics (Table 1). No mean differences were found for maternal age $(p=.65)$, maternal education $(p=$ .52), number of siblings ( $p=.23$ ), breastfeeding time-period (in months) between infants who consumed and infants who did not consume antibiotics in the first nine months of life $(p=.83)$ (Table 1).

Using binary logistic regression analysis, we tested the four significant variables

312 from the above t-student analysis (maternal sensitivity, infant cooperative behavior, 313 Apgar at $1^{\text {st }}$ and $5^{\text {th }}$ minute $)$ and found that maternal sensitivity $(p=.02)$ was negatively 314 associated with antibiotics uptake (Table 2).

No significant differences were found according to type of labor $\left(\chi^{2}(1,134)=.691 ; p\right.$

$316=.406)$, enrollment in daycare $\left(\chi^{2}(1,134)=3.570 ; p=.059\right)$, nor according to infant gender $317\left(\chi^{2}(1,134)=.827 ; p=.363\right)$ and antibiotics uptake. In our study, $60.4 \%$ of infants born vaginally and $39.6 \%$ of infants born non-vaginally consumed antibiotics before 
completing 9-months. From the group of infants who attended daycare, 51.2\% consumed antibiotics, and $34.1 \%$ of infants reared at home consumed antibiotics. The proportion of ambivalent-attached infants enrolled in daycare was $20.9 \%$ and of securely-attached infants was $53.5 \%$. The only three ambivalent-attached infants, who consumed antibiotics, were attending daycare. Moreover, among infants reared at home, $90.4 \%$ (=38/42) of secure-attached infants did not take antibiotics, which contrasts with $15.0 \%(=3 / 20)$ of ambivalent-attached infants. Also, $35.1 \%$ of the girls and $42.9 \%$ of the boys consumed antibiotics.

\section{Attachment patterns and antibiotics' uptake}

Our sample comprised $29.8 \%$ of infants classified as insecure-avoidant attached, $48.5 \%$ classified as secure, and $21.6 \%$ classified as insecure-resistant. This level of security is lower than the mean among Western countries of $67 \%$ (van ljzendoorn \& Sagi-Schwartz, 2008). However, a literature systematic review has shown that attachment security varies between $45 \%$ and $65 \%$ in Portuguese samples (reviewed by Faria, Lopes-dos-Santos, \& Fuertes, 2014).

When comparing mother-infant attachment classification between infants that used antibiotics with those that did not use antibiotics, we found that ambivalentattached infants were more likely to have received these drugs than secure or avoidant attached infants $\left(\chi^{2}(1,134)=40.103 ; p<.001\right.$; Table 3$)$. Indeed, 89.7\% (26/29) of infants classified as ambivalent in the Strange Situation at 12 months were treated with 
340 antibiotics in their first nine months of life, whereas only $32.5 \%(13 / 40)$ of avoidant and

$34121.5 \%(14 / 65)$ of securely attached infants have been treated with antibiotics in the 342 same period (Table 3).

Given that there was no significant difference between secure and avoidant

344 attachment patterns, we conducted further analyses combining both attachment groups

$345\left(\chi^{2}(1,134)=38.859 ; p<.001\right)$. Moreover, for children with insecure-ambivalent

346 attachment, the odds of antibiotic consumption were 25.037 (95\% confidence interval,

347 7.012-89.394) times higher than children with the other patterns of attachment (secure

348 and avoidant attachment combined).

\section{Discussion}

This is the first study to explore a link between infant attachment and antibiotic prescription, as well as to study the factors associated with antibiotic prescription among a range of maternal and infant factors. From all variables included in this study, maternal sensitivity had the highest impact on antibiotic uptake until infants' nine months of age. The fact that a maternal variable is a crucial factor explaining antibiotic consumption, rather than others factors, including infant variables (e.g., breastfeeding, Apgar at $1^{\text {st }}$ and $5^{\text {th }}$ min, GA, or GW) or environmental conditions such as infants raising

357 conditions and socio-demographic variables (e.g., maternal education, maternal age, number of siblings) is a striking result, particularly because those variables are usually

359 related with infant's health conditions or the likelihood of contagion by bacteria

360 (Pettigrew et al., 2003; Thacker, Addiss, Goodman, Holloway, \& Spencer, 1992; 
361 Thompson, Monteagudo-Mere, Cadenae, Lampi, \& Azcarate-Peril, 2015). In line with

362 our results, past research has shown that mothers with a high score in the sensitivity

363 scales tend to be highly sensitive in comforting and caring for their infants when ill

364 (Belsky, 1999; DeWolff \& van ljzendoorn, 1997; Lucassen et al., 2011). In general,

365 these mothers are better at interpreting infant's needs and cues, eventually giving a

366 prompt response in case of a disease, and attenuating symptoms and somatization (for

367 a review, see P. J. Meredith \& Strong, 2019).

Less sensitive mothers tend to be more anxious and to have more negative perceptions of their infants' health condition (McCallum \& McKim, 1999). We speculate that these mothers described their infants' symptoms less precisely (e.g., reporting more days of fever), leading physicians to believe that infants had a bacterial disease. Moreover, physicians may perceive maternal expectations for an antibiotic prescription.

373 This relates to another study that found that physicians' perception of parental expectations of antibiotic prescription (i.e., the physicians perceived parental pressure

375 for antibiotic prescription) was the only significant predictor of antimicrobials prescription 376 in conditions of presumed viral etiology (Mangione-Smith, McGlynn, Elliott, Krogstad, \& 377 Brook, 1999). In sum, possibly, maternal behavior affects the likelihood of antibiotic 378 prescription.

Attending a daycare is usually associated with increased contagion rates. For example, in a literature review, Thacker et al (1992) have shown that the risk of some 381 infectious diseases was at least two times higher among children attending daycare 382 than among infants reared at home (Thacker et al., 1992); see also refs. (Pettigrew et 
383

384

385

386

al., 2003; Thompson et al., 2015). However, in our study, the proportion of infants consuming antibiotics is slightly lower among those attending a daycare than among those reared at home. Yet, the only three ambivalent infants that did not take antibiotics were not attending daycare, which does not support the thesis that other family and educational contexts can buffer the social-emotional effect of insecure attachment (Biringen et al., 2012). Nevertheless, this result should be taken with caution taking into consideration that this was observed in only a few cases.

We further investigated the link between infant attachment patterns and antibiotic consumption. As hypothesized, our results show that the prevalence of antibiotic consumption until 9-months of age is significantly higher in insecure-ambivalent attached infants than among other infants. Indeed, ambivalent-attached infants tend to react to stressful events and pain with overwhelmed and angry behaviors while resisting mothers' attempts to soothe their distress (Mills-Koonce, Propper, \& Barnett, 2012). These reactions are expected in the presence of health problems, leaving parents overconcerned, and feeling helpless in responding to their infants' needs (Feeney \& Ryan, 1994; Scher \& Mayseless, 2000). Pressing doctors to prescribe antibiotics can be a result of the parents' sense of helplessness. Indeed, it is known that facing parents' lack of effectiveness, infants become distrustful and uncertain that their parents serve as a secure-base (McElwain \& Booth-LaForce, 2006). According to attachment theory, these experiences and expectations (secure based scripts) are internalized in infants' working attachment models, thereby affecting infants' emotional development (Barbosa, Beeghly, Moreira, Tronick, \& Fuertes, 2020; Beebe et al., 
2010; Bowlby, 1969). The lack of sense of trust and of the ability to rely on others generated by early interactions lead to emotional regulatory problems, unbalanced social information processing, lack of resilience in relationships, and emotional maladjustment (e.g., Belsky, Friedman, \& Hsieh, 2001; Cassidy, 1994; Elicker, Englund, \& Sroufe, 1992; Greenberg, Speltz, \& Deklyen, 1993; Kochanska, Barry, Stellern, \& O'Bleness, 2009).

The associations between antibiotic consumption and the development of later diseases (Ajslev et al., 2011; Francino, 2016; Risnes et al., 2011), as well as the risk of increased antibiotic resistance (Friedman et al., 2016), have concerned microbiologists, epidemiologists, and health practitioners in general. In the present study, $39.6 \%$ of the infants had already consumed antibiotics before completing nine months of life, which agrees with another study showing that $54 \%$ of Portuguese infants consumed antibiotics in the first 12 months of life (ISAAC, 2011).

Antibiotic uptake has also been associated with mental problems, most likely through microbiota disruption (Francino, 2016). For example, it was recently shown that the microbiota of people with depression was depleted of the same two bacterial species (Valles-Colomer et al., 2019). Although performed with adults, that study suggests that antibiotics may also impact infants' behavior. It could be argued that our study does not rule out the alternative hypothesis that infants became insecurely attached due to antibiotic uptake That is, the uptake of antibiotics during the first nine months of life could have triggered a cascade of physiological and regulatory processes contributing for an insecure-ambivalent pattern when infants completed 12 months. 
427 Contrary to this hypothesis, it was maternal sensitivity that had the highest association 428 with antibiotic uptake. On the other hand, the infant cooperativity is also associated with 429 antibiotic uptake, a variable that is related to maternal sensitivity (Crittenden \& 430 Bonvillian, 1984; Fuertes, Faria, Soares, \& Crittenden, 2008). It is, therefore, our opinion 431 that the causal connection between these variables must be further investigated.

Finding that antibiotics are prescribed more often to insecure-attached infants 433 than to infants classified otherwise, may be viewed with some concern, and needs 434 further research. Even when we replicated the analysis with a more heterogeneous sample (with the original sample of 176 mother-infant dyads), which includes, for example, preterms, or infants with chronic diseases, analogous results are obtained (Supplementary Information Table S1 and S2). Futures studies should include qualitative and phenomenological research to gather more and deeper information regarding maternal representations about antibiotics efficacy and drawbacks, doctorpatient relationship, and mothers' role as caregivers when their infants are ill.

Regarding intervention, health services must improve communication with parents, explaining to them both that antibiotics are both advantageous and disadvantageous. Moreover, our results reinforce the need to enhance doctor-family relationships based on open and empathic communication focused on responding to parents' concerns (Becker, Lin, \& Miller, 2018). Based on prior research (BakermansKranenburg, van IJzendoorn, \& Juffer, 2003), to prevent attachment insecurity and their consequences on infants' and parents' behavior, a family-centered approach (as, for 
448 example, The Circle of Security) can help moderate infant and parental stress levels

449 (Palermo \& Chambers, 2005).

\section{Limitations, strengths, and future directions}

The present study has both limitations and strengths that should be considered when evaluating the results. One limitation is that the current sample of Portuguese motherinfant dyads was mostly from low-risk socioeconomic backgrounds and homogeneous in race/ethnicity Thus, our findings may not generalize to mother-infant dyads in other ethnic/racial groups, geographic locations, and may not characterize infants' social interactions with other caregivers such as fathers or extended family members. A third limitation is the relatively small sample size $(N=134)$, which may have limited statistical power. Replication of the current study in larger, more diverse samples and included fathers is needed. The primary strengths of the current study include its prospective, longitudinal measures (at 9 and 12 months), the inclusion of a well-described observational paradigm (Strange Situation) and free play observations, and the use of detailed behavioral coding systems.

It may be helpful to learn more about maternal reactions and anxiety especially when their infants are ill (McClure, Brennan, Hammen, \& Le Brocque, 2001; StevensonHinde, Shouldice, \& Chicot, 2011; Whaley, Pinto, \& Sigman, 1999). Although we assessed maternal interactive behavior, maternal anxiety was not directly assessed in our study and we believe that this can be an important aspect to investigate in future studies (McElwain \& Booth-LaForce, 2006). Infants' health problems during the first nine 
469 months of life may trigger a cascade of reactions, and the measurement of maternal

470 anxiety could help us to understand the impact of ambivalent attachment behavior on

471 their mothers. According to Sameroff and Fiese`s Transactional Model (Sameroff \&

472 Fiese, 2000), it is likely that, in face of infants' expression of pain and discomfort,

473 parental stress increases and contributes to raising, even more, infant physiological and

474 behavioral responses (Boyce \& Ellis, 2005; Propper \& Moore, 2006). This reciprocal

475 process should be studied in the future.

\section{Declaration of conflicting interests}

478 The authors declared no potential conflicts of interest with respect to the research, 479 authorship, and publication of this article. 
Ainsworth, M. D., Blehar, M., Waters, E., \& Wall, S. (1978). Patterns of attachment - A Psychological Study of the Strange Situation.: Lawerence Erlbaum Associates: New Jersey.

Ainsworth, M. D. S., Bell, S. M., \& Stayton, D. J. (1974). Infant-mother attachment and social development: Socialization' as product of reciprocal responsiveness to signals. . In M. Richards (Ed.), The integration of a child into a social world (pp. 9-135). London: Cambridge University Press.

Ajslev, T. A., Andersen, C. S., Gamborg, M., Sorensen, T. I., \& Jess, T. (2011). Childhood overweight after establishment of the gut microbiota: the role of delivery mode, pre-pregnancy weight and early administration of antibiotics. Int J Obes (Lond), 35(4), 522-529. Retrieved from http://www.ncbi.nlm.nih.gov/pubmed/21386800. doi:10.1038/ijo.2011.27

Altiner, A., Brockmann, S., Sielk, M., Wilm, S., Wegscheider, K., \& Abholz, H. H. (2007). Reducing antibiotic prescriptions for acute cough by motivating GPs to change their attitudes to communication and empowering patients: a cluster-randomized intervention study. Journal of Antimicrobial Chemotherapy, 60(3), 638-644. Retrieved from <Go to ISI>://WOS:000249882200026. doi:10.1093/jac/dkm254

Andrews, N. E., Meredith, P. J., \& Strong, J. (2011). Adult attachment and reports of pain in experimentally-induced pain. European Journal of Pain, 15(5), 523-530. Retrieved from <Go to ISI>://WOS:000290559700013. doi:10.1016/j.ejpain.2010.10.004

Arroll, B., Kenealy, T., \& Kerse, N. (2003). Do delayed prescriptions reduce antibiotic use in respiratory tract infections? A systematic review. British Journal of General Practice, 53(496), 871-877. Retrieved from $<$ Go to ISI $>$ ://WOS:000187240000010.

Bakermans-Kranenburg, M. J., van IJzendoorn, M. H., \& Juffer, F. (2003). Less is more: Meta-analyses of sensitivity and attachment interventions in early childhood. Psychological Bulletin, 129(2), 195-215. Retrieved from <Go to ISI>://WOS:000181707800002. doi:10.1037/0033-2909.129.2.195

Barbosa, M., Beeghly, M., Moreira, J., Tronick, E., \& Fuertes, M. (2018). Robust Stability and Physiological Correlates of Infants' Patterns of Regulatory Behavior in the Still-Face Paradigm at 3 and 9 Months. Developmental Psychology, 54(11), 2032-2042. Retrieved from <Go to ISI >://WOS:000448187100003. doi:10.1037/dev0000616

Barbosa, M., Beeghly, M., Moreira, J., Tronick, E., \& Fuertes, M. (2020). Emerging patterns of infant regulatory behavior in the Still-Face paradigm at 3 and 9 months predict mother-infant attachment at 12 months. Attachment \& Human Development, 1-17. Retrieved from https://www.ncbi.nlm.nih.gov/pubmed/32363996. doi:10.1080/14616734.2020.1757730

Becker, T. D., Lin, H. C., \& Miller, V. A. (2018). A pilot study of observed physician-parent-child communication and child satisfaction in a gastroenterology clinic. Patient Preference and Adherence, 12, 1327-1335. Retrieved from <Go to ISI >://WOS:000439921200001. doi:10.2147/Ppa.S171620

Beebe, B., Jaffe, J., Markese, S., Buck, K., Chen, H., Cohen, P., . . Feldstein, S. (2010). The origins of 12-month attachment: A microanalysis of 4-month mother-infant interaction. Attachment \& Human Development, 12(1-2), 3-141. Retrieved from <Go to ISI >://WOS:000276022900002. doi:10.1080/14616730903338985 
Beeghly, M., Fuertes, M., Liu, C. H., Delonis, M. S., \& Tronick, E. (2011). Maternal sensitivity in dyadic context: Mutual regulation, meaning-making, and reparation. In D. W. Davis \& M. C. Logsdon (Eds.), Maternal sensitivity: A scientific foundation for practice. (pp. 59-83). NY: Nova Science Publishers.

Belsky, J. (1999). Interactional and contextual determinants of attachment security. . In J. Cassidy \& P. R. Shaver (Eds.), Handbook of attachment: Theory, research, and clinical implications. (pp. 249-264). New York: The Guilford Press.

Belsky, J., Friedman, S. L., \& Hsieh, K. H. (2001). Testing a core emotion-regulation prediction: Does early attentional persistence moderate the effect of infant negative emotionality on later development? Child Development, 72(1), 123-133. Retrieved from <Go to ISI>://WOS:000167143800008. doi:Doi $10.1111 / 1467-8624.00269$

Biringen, Z., Altenhofen, S., Aberle, J., Baker, M., Brosal, A., Bennett, S., . . Swaim, R. (2012). Emotional availability, attachment, and intervention in center-based child care for infants and toddlers. Development and Psychopathology, 24(1), 23-34. Retrieved from <Go to ISI>://WOS:000300270600003. doi:10.1017/S0954579411000630

Bowlby, J. (1969). Attachment and loss. (Vol. I). London: Penguin Book.

Boyce, W. T., \& Ellis, B. J. (2005). Biological sensitivity to context: I. An evolutionary-developmental theory of the origins and functions of stress reactivity. Development and Psychopathology, 17(2), 271-301. Retrieved from <Go to ISI > //WOS:000229244700001. doi:10.1017/S0954579405050145

Braungart-Rieker, J. M., Garwood, M. M., Powers, B. P., \& Wang, X. Y. (2001). Parental sensitivity, infant affect, and affect regulation: Predictors of later attachment. Child Development, 72(1), 252-270. Retrieved from <Go to ISI>://WOS:000167143800016. doi:Doi 10.1111/1467-8624.00277

Bretherton, I. (1992). The Origins of Attachment Theory - Bowlby,John and Ainsworth,Mary. Developmental Psychology, 28(5), 759-775. Retrieved from <Go to ISI>://WOS:A1992JM42000002. doi:Doi 10.1037//0012-1649.28.5.759

Buffie, C. G., \& Pamer, E. G. (2013). Microbiota-mediated colonization resistance against intestinal pathogens. Nat Rev Immunol, 13(11), 790-801. Retrieved from http://www.ncbi.nlm.nih.gov/pubmed/24096337. doi:10.1038/nri3535

Cassibba, R., van Ijzendoorn, M. H., Bruno, S., \& Coppola, G. (2004). Attachment of mothers and children with recurrent asthmatic bronchitis. Journal of Asthma, 4l(4), 419-431. Retrieved from < Go to ISI >://WOS:000222805700005. doi:10.1081/Jas-120033984

Cassidy, J. (1994). Emotion regulation: Influences of attachment relationships. In N. Fox (Ed.), The development of emotion regulation (Vol. 59 (2-3), pp. 228-249).

Cassidy, J., \& Shaver, P. R. (Eds.). (2018). Handbook of Attachment - Theory, Research, and Clinical Applications (3rd ed.). New York: Guilford Press.

Cicchetti, D. V. (1994). Guidelines, criteria, and rules of thumb for evaluating normed and standardized assessment instruments in psychology. Psychological Assessment, 6(4), 284-290. doi:10.1037/1040-3590.6.4.284

Crittenden, P. M. (2003). CARE-Index Manual. Miami: Family Relations Institute. 
Crittenden, P. M., \& Bonvillian, J. D. (1984). The Relationship between Maternal Risk Status and Maternal Sensitivity. American Journal of Orthopsychiatry, 54(2), 250-262. Retrieved from <Go to ISI >://WOS:A1984SM66900005. doi:DOI 10.1111/j.1939-0025.1984.tb01492.x

DeWolff, M. S., \& van Ijzendoorn, M. H. (1997). Sensitivity and attachment: A meta-analysis on parental antecedents of infant attachment. Child Development, 68(4), 571-591. Retrieved from <Go to ISI>://WOS:A1997XU15800001. doi:DOI:10.2307/1132107

Elicker, J., Englund, M., \& Sroufe, L. A. (1992). SroufePredicting peer competence and peer relationships in childhood from early parent-child relationships. In R. Parke \& G. Ladd (Eds.), Family-peer relations: Modes of linkage (pp. 77-106). Hillsdale, NJ: Lawrence Erlbaum.

Faria, A., Lopes-dos-Santos, P., \& Fuertes, M. (2014). Pais e mães protegem, acarinham e brincam de formas diferentes. Análise Psicológica, 32(4), 419-437. doi:doi: 10.14417/ap.698

Feeney, J. A. (2000). Implications of attachment style for patterns of health and illness. Child Care Health and Development, 26(4), 277-288. Retrieved from <Go to ISI>://WOS:000089055500003. doi:DOI 10.1046/j.1365-2214.2000.00146.x

Feeney, J. A., \& Ryan, S. M. (1994). Attachment Style and Affect Regulation - Relationships with Health Behavior and Family Experiences of Illness in a Student Sample. Health Psychology, 13(4), 334-345. Retrieved from <Go to ISI>://WOS:A1994NY56000006. doi:Doi 10.1037/0278-6133.13.4.334

Fletcher-Lartey, S., Yee, M., Gaarslev, C., \& Khan, R. (2016). Why do general practitioners prescribe antibiotics for upper respiratory tract infections to meet patient expectations: a mixed methods study. BMJ Open, 6(10), e012244. Retrieved from http://www.ncbi.nlm.nih.gov/pubmed/27798010. doi:10.1136/bmjopen-2016012244

Francino, M. P. (2016). Antibiotics and the Human Gut Microbiome: Dysbiose sand Accumulation of Resistances. Frontiers in Microbiology, 6. Retrieved from <Go to ISI>://WOS:000443482900001. doi:10.3389/Fmicb.2015.01543

Friedman, N. D., Temkin, E., \& Carmeli, Y. (2016). The negative impact of antibiotic resistance. Clin Microbiol Infect, 22(5), 416-422. Retrieved from http://www.ncbi.nlm.nih.gov/pubmed/26706614. doi:10.1016/j.cmi.2015.12.002

Fuertes, M., Faria, A., Soares, H., \& Crittenden, P. (2008). Mother-child patterns of interaction: the impact of premature birth and social economical background. Actha Ethologica, 12, 1-11. doi:1007/s10211-008$0051-4$

Fuertes, M., Justo, J., Barbosa, M., Leopoldo, L., Lopes, J., Gomes Pedro, J., \& Sparrow, J. (2012). Infants prematurely born: Socio-emotional Development and Early Intervention. In D. Contreiras \& J. Sampaio (Eds.), Preterm Infants: Development, Prognosis and Potential Complications (pp. 100-125). NY: Nova Science Publishers, Inc. .

Greenberg, M. T., Speltz, M. L., \& Deklyen, M. (1993). The Role of Attachment in the Early Development of Disruptive Behavior Problems. Development and Psychopathology, 5(1-2), 191-213. Retrieved from <Go to ISI $>$ ://WOS:A1993LJ43100013. doi:Doi 10.1017/S095457940000434x

Houghteling, P. D., \& Walker, W. A. (2015). Why Is Initial Bacterial Colonization of the Intestine Important to Infants' and Children's Health? Journal of Pediatric Gastroenterology and Nutrition, 60(3), 294-307. Retrieved from <Go to ISI $>$ ://WOS:000350527100008. doi:10.1097/Mpg.0000000000000597 
INE. (2011). Indicadores Sociais 2011. 215. Retrieved from https://www.ine.pt/xportal/xmain?xpid=INE\&xpgid=ine publicacoes\&PUBLICACOESpub boui=149279 938\&PUBLICACOESmodo $=2$

ISAAC. (2011). International Study of Asthma and Allergies in Childood (ISAAC) - 20 anos em Portugal. Acta Pediátrica Portuguesa - Sociedade Portuguesa de Pediatria, 42(5), Suplemento II - S25 - S48.

Jakobsson, H. E., Abrahamsson, T. R., Jenmalm, M. C., Harris, K., Quince, C., Jernberg, C., . . Andersson, A. F. (2014). Decreased gut microbiota diversity, delayed Bacteroidetes colonisation and reduced Th1 responses in infants delivered by caesarean section. Gut, 63(4), 559-566. Retrieved from http://www.ncbi.nlm.nih.gov/pubmed/23926244. doi:10.1136/gutjnl-2012-303249

Kochanska, G., Barry, R. A., Stellern, S. A., \& O'Bleness, J. J. (2009). Early Attachment Organization Moderates the Parent-Child Mutually Coercive Pathway to Children's Antisocial Conduct. Child Development, 80(4), 1288-1300. Retrieved from <Go to ISI >://WOS:000268051200024. doi:DOI 10.1111/j.14678624.2009.01332.x

Kronman, M. P., Zhou, C., \& Mangione-Smith, R. (2014). Bacterial prevalence and antimicrobial prescribing trends for acute respiratory tract infections. Pediatrics, 134(4), e956-965. Retrieved from http://www.ncbi.nlm.nih.gov/pubmed/25225144. doi:10.1542/peds.2014-0605

Landis, J. R., \& Koch, G. G. (1977). The measurement of observer agreement for categorical data. Biometrics, 33(1), 159-174. Retrieved from https://www.ncbi.nlm.nih.gov/pubmed/843571.

Lewis, M., Feiring, C., Mcguffog, C., \& Jaskir, J. (1984). Predicting Psychopathology in 6-Year-Olds from Early Social-Relations. Child Development, 55(1), 123-136. Retrieved from <Go to ISI>://WOS:A1984SE98400010. doi:Doi 10.2307/1129839

Little, P., Gould, C., Williamson, I., Warner, G., Gantley, M., \& Kinmonth, A. L. (1997). Reattendance and complications in a randomised trial of prescribing strategies for sore throat: the medicalising effect of prescribing antibiotics. British Medical Journal, 315(7104), 350-352. Retrieved from <Go to ISI>://WOS:A1997XQ86400023.

Lucassen, N., Tharner, A., Van IJzendoorn, M. H., Bakermans-Kranenburg, M. J., Volling, B. L., Verhulst, F. C., . . . Tiemeier, H. (2011). The Association Between Paternal Sensitivity and Infant-Father Attachment Security: A Meta-Analysis of Three Decades of Research. Journal of Family Psychology, 25(6), 986-992. Retrieved from <Go to ISI>://WOS:000298046200019. doi:10.1037/a0025855

Main, M., \& Solomon, J. (1990). Procedures for identifying infants as disorganized/disoriented during the Ainsworth Strange Situation. In M. Greenberg, D. Cicchetti, \& E. Cummings (Eds.), Attachment in the Preschool Years: Theory, Research and Intervention (pp. 121-160). Chicago, IL, US: Chicago University Press.

Mangione-Smith, R., McGlynn, E. A., Elliott, M. N., Krogstad, P., \& Brook, R. H. (1999). The relationship between perceived parental expectations and pediatrician antimicrobial prescribing behavior. Pediatrics, 103(4), 711-718. Retrieved from <Go to ISI >://WOS:000079515400002. doi:DOI 10.1542/peds.103.4.711

Martinez-Gonzalez, N. A., Coenen, S., Plate, A., Colliers, A., Rosemann, T., Senn, O., \& Neuner-Jehle, S. (2017). The impact of interventions to improve the quality of prescribing and use of antibiotics in primary care patients with respiratory tract infections: a systematic review protocol. BMJ Open, 7(6). Retrieved from $\leq$ Go to ISI >://WOS:000406391200218. doi:ARTN e016253 10.1136/bmjopen-2017-016253 
McCallum, M. S., \& McKim, M. K. (1999). Recurrent Otitis Media and Attachment Security: A Path Model. Early Education and Development, 10(4), 517-534. doi:10.1207/s15566935eed1004_6

McClure, E. B., Brennan, P. A., Hammen, C., \& Le Brocque, R. M. (2001). Parental anxiety disorders, child anxiety disorders, and the perceived parent-child relationship in an Australian high-risk sample. Journal of Abnormal Child Psychology, 29(1), 1-10. Retrieved from <Go to ISI>://WOS:000167633300001. doi:Doi 10.1023/A:1005260311313

McElwain, N. L., \& Booth-LaForce, C. (2006). Maternal sensitivity to infant distress and nondistress as predictors of infant-mother attachment security. Journal of Family Psychology, 20(2), 247-255. Retrieved from <Go to ISI >://WOS:000238333900008. doi:10.1037/0893-3200.20.2.247

Meredith, P., Ownsworth, T., \& Strong, J. (2008). A review of the evidence linking adult attachment theory and chronic pain: Presenting a conceptual model. Clinical Psychology Review, 28(3), 407-429. Retrieved from $<$ Go to ISI>://WOS:000254791900004. doi:10.1016/j.cpr.2007.07.009

Meredith, P. J., \& Strong, J. (2019). Attachment and chronic illness. Current Opinion in Psychology, 25, 132-138. Retrieved from <Go to ISI>://WOS:000460348100024. doi:10.1016/j.copsyc.2018.04.018

Mesman, J., Oster, H., \& Camras, L. (2012). Parental sensitivity to infant distress: what do discrete negative emotions have to do with it? Attachment \& Human Development, 14(4), 337-348. Retrieved from <Go to ISI>://WOS:000305529400001. doi:10.1080/14616734.2012.691649

Mills-Koonce, W. R., Propper, C. B., \& Barnett, M. (2012). Poor infant soothability and later insecure-ambivalent attachment: Developmental change in phenotypic markers of risk or two measures of the same construct? Infant Behavior \& Development, 35(2), 215-225. Retrieved from <Go to ISI >://WOS:000303033700005. doi:10.1016/j.infbeh.2012.01.002

Neumark, T., Brudin, L., \& Molstad, S. (2010). Use of rapid diagnostic tests and choice of antibiotics in respiratory tract infections in primary healthcare--a 6-y follow-up study. Scand J Infect Dis, 42(2), 90-96. Retrieved from http://www.ncbi.nlm.nih.gov/pubmed/19902992. doi:10.3109/00365540903352932

Palermo, T. M., \& Chambers, C. T. (2005). Parent and family factors in pediatric chronic pain and disability: An integrative approach. Pain, 119(1-3), 1-4. Retrieved from <Go to ISI>://WOS:000234355900001. doi:10.1016/j.pain.2005.10.027

Pettigrew, M. M., Khodaee, M., Gillespie, B., Schwartz, K., Bobo, J. K., \& Foxman, B. (2003). Duration of breastfeeding, daycare, and physician visits among infants 6 months and younger. Annals of Epidemiology, 13(6), 431-435. Retrieved from <Go to ISI>://WOS:000184370300006. doi:10.1016/S10472797(02)00463-5

Pietromonaco, P. R., \& Powers, S. I. (2015). Attachment and health-related physiological stress processes. Current Opinion in Psychology, 1, 34-39. Retrieved from <Go to ISI>://WOS:000364778100008. doi:10.1016/j.copsyc.2014.12.001

Propper, C., \& Moore, G. A. (2006). The influence of parenting on infant emotionality: A multi-level psychobiological perspective. Developmental Review, 26(4), 427-460. Retrieved from <Go to ISI >://WOS:000242872800003. doi:10.1016/j.dr.2006.06.003

Rautava, S. (2016). Early microbial contact, the breast milk microbiome and child health. J Dev Orig Health Dis, 7(1), 5-14. Retrieved from http://www.ncbi.nlm.nih.gov/pubmed/26051698. doi: $10.1017 /$ S2040174415001233 
Rautava, S., \& Walker, W. A. (2009). Academy of Breastfeeding Medicine founder's lecture 2008: breastfeeding-an extrauterine link between mother and child. Breastfeed Med, 4(1), 3-10. Retrieved from http://www.ncbi.nlm.nih.gov/pubmed/19292608. doi:10.1089/bfm.2009.0004

Risnes, K. R., Belanger, K., Murk, W., \& Bracken, M. B. (2011). Antibiotic exposure by 6 months and asthma and allergy at 6 years: Findings in a cohort of 1,401 US children. Am J Epidemiol, 173(3), 310-318. Retrieved from http://www.ncbi.nlm.nih.gov/pubmed/21190986. doi:10.1093/aje/kwq400

Sameroff, A. J., \& Fiese, B. H. (2000). Transactional regulation: The developmental ecology of early intervention. In S. J. Meisels \& J. P. Shonkoff (Eds.), Handbook of Early Childhood Intervention (pp. 135-159). New York, NY, US: Cambridge University Press.

Sassone-Corsi, M., \& Raffatellu, M. (2015). No vacancy: how beneficial microbes cooperate with immunity to provide colonization resistance to pathogens. J Immunol, 194(9), 4081-4087. Retrieved from http://www.ncbi.nlm.nih.gov/pubmed/25888704. doi:10.4049/jimmunol.1403169

Scher, A., \& Mayseless, O. (2000). Mothers of anxious/ambivalent infants: Maternal characteristics and child-care context. Child Development, 71(6), 1629-1639. Retrieved from <Go to ISI>://WOS:000166097700013. doi:Doi 10.1111/1467-8624.00253

Schuez-Havupalo, L., Toivonen, L., Karppinen, S., Kaljonen, A., \& Peltola, V. (2017). Daycare attendance and respiratory tract infections: a prospective birth cohort study. BMJ Open, 7(9). Retrieved from <Go to ISI>://WOS:000412650700021. doi:10.1136/bmjopen-2016-014635

Simmons, R. J., Goldberg, S., Washington, J., Fischerfay, A., \& Maclusky, I. (1995). Infant-Mother Attachment and Nutrition in Children with Cystic-Fibrosis. Journal of Developmental and Behavioral Pediatrics, 16(3), 183-186. Retrieved from <Go to ISI>://WOS:A1995RE37400006.

Sirota, M., Round, T., Samaranayaka, S., \& Kostopoulou, O. (2017). Expectations for Antibiotics Increase Their Prescribing: Causal Evidence About Localized Impact. Health Psychology, 36(4), 402-409. Retrieved from <Go to ISI>://WOS:000398912300012. doi:10.1037/hea0000456

Stevenson-Hinde, J., Shouldice, A., \& Chicot, R. (2011). Maternal anxiety, behavioral inhibition, and attachment. Attachment \& Human Development, 13(3), 199-215. Retrieved from <Go to ISI > :/WOS:000289803800001. doi:Pii 936575559

$10.1080 / 14616734.2011 .562409$

Thacker, S. B., Addiss, D. G., Goodman, R. A., Holloway, B. R., \& Spencer, H. C. (1992). Infectious-Diseases and Injuries in Child Day-Care - Opportunities for Healthier Children. Jama-Journal of the American Medical Association, 268(13), 1720-1726. Retrieved from <Go to ISI>://WOS:A1992JQ37600035. doi:DOI 10.1001/jama.268.13.1720

Thompson, A. L., Monteagudo-Mere, A., Cadenae, M. B., Lampi, M. L., \& Azcarate-Peril, M. A. (2015). Milk- and solid-feeding practices and daycare attendance are associated with differences in bacterial diversity, predominant communities, and metabolic and immune function of the infant gut microbiome. Frontiers in Cellular and Infection Microbiology, 5. Retrieved from <Go to ISI >://WOS:000349159900001. doi:10.3389/fcimb.2015.00003

Tyrstrup, M., van der Velden, A., Engstrom, S., Goderis, G., Molstad, S., Verheij, T., ... Adriaenssens, N. (2017). Antibiotic prescribing in relation to diagnoses and consultation rates in Belgium, the Netherlands and 
Sweden: use of European quality indicators. Scand J Prim Health Care, 35(1), 10-18. Retrieved from http://www.ncbi.nlm.nih.gov/pubmed/28277045. doi:10.1080/02813432.2017.1288680

Valles-Colomer, M., Falony, G., Darzi, Y., Tigchelaar, E. F., Wang, J., Tito, R. Y., . . Raes, J. (2019). The neuroactive potential of the human gut microbiota in quality of life and depression. Nat Microbiol, 4(4), 623-632. Retrieved from <Go to ISI>://WOS:000461999200015. doi:10.1038/s41564-018-0337-X

van Ijzendoorn, M. H., \& Sagi-Schwartz, A. (2008). Cross-cultural patterns of attachment: Universal and contextual dimensions. . In J. Cassidy \& P. R. Shaver (Eds.), Handbook of attachment: Theory, research, and clinical applications. (pp. 880-905). New York: The Guilford Press.

Whaley, S. E., Pinto, A., \& Sigman, M. (1999). Characterizing interactions between anxious mothers and their children. Journal of Consulting and Clinical Psychology, 67(6), 826-836. Retrieved from <Go to ISI>://WOS:000083979000002. doi:Doi 10.1037/0022-006x.67.6.826

Wood, F., Phillips, C., Brookes-Howell, L., Hood, K., Verheij, T., Coenen, S., . . Butler, C. C. (2013). Primary care clinicians perceptions of antibiotic resistance: a multi-country qualitative interview study. Journal of Antimicrobial Chemotherapy, 68(1), 237-243. Retrieved from <Go to ISI>://WOS:000312646300037. doi:10.1093/jac/dks338

Zaporowska-Stachowiak, I., Stachowiak, K., \& Stachnik, K. (2019). Two is a perfect number: Patient-doctor relationship and patient attachment style in palliative care. Journal of Health Psychology, 24(5), 549-560. Retrieved from <Go to ISI>://WOS:000462080200001. doi:10.1177/1359105317721307 
734 Table $1 \mid$ T-test for mean differences of infant and maternal factors according to antibiotics 735 consumption

\begin{tabular}{|c|c|c|c|c|c|c|c|c|}
\hline & \multirow{2}{*}{\multicolumn{3}{|c|}{ Uptake of antibiotics }} & \multirow{2}{*}{\multicolumn{3}{|c|}{ No uptake of antibs. }} & \multirow[b]{3}{*}{$t$} & \multirow[b]{3}{*}{$p$} \\
\hline & & & & & & & & \\
\hline & Mean & $(S D)$ & $N$ & Mean & $(S D)$ & $N$ & & \\
\hline Breastfeeding (in months) & 3.85 & 2.60 & 53 & 3.95 & 2.60 & 81 & .811 & .826 \\
\hline Maternal sensitivity & 7.09 & 2.19 & 46 & 8.22 & 2.30 & 74 & 2.697 & .008 \\
\hline Maternal control & 4.59 & 2.95 & 46 & 3.61 & 2.92 & 74 & 1.775 & .079 \\
\hline Maternal unresponsivity & 2.26 & 2.74 & 46 & 2.16 & 2.39 & 74 & .209 & .840 \\
\hline Infant cooperative behavior & 7.11 & 2.38 & 46 & 8.20 & 2.21 & 74 & 2.518 & .014 \\
\hline Infant compulsive behavior & 2.72 & 3.27 & 46 & 1.61 & 2.81 & 74 & 1.905 & .060 \\
\hline Infant difficult behavior & 2.63 & 2.85 & 46 & 2.20 & 2.66 & 74 & .820 & .414 \\
\hline Infant passive behavior & 1.89 & 2.11 & 47 & 1.93 & 2.00 & 74 & .101 & .920 \\
\hline Gestational Age & 37.68 & 2.27 & 53 & 37.54 & 2.44 & 81 & .337 & .737 \\
\hline Gestational Weight & 2911.42 & 574.67 & 53 & 3043.26 & 649.43 & 81 & 1.233 & .220 \\
\hline Apgar $1^{\text {st }}$ minute & 8.87 & .44 & 52 & 8.50 & 1.22 & 74 & 2.365 & .020 \\
\hline Apgar $5^{\text {th }}$ minute & 9.88 & .32 & 52 & 9.59 & .93 & 76 & 2.537 & .013 \\
\hline Maternal age & 30.51 & 5.14 & 53 & 30.09 & 5.31 & 81 & .459 & .647 \\
\hline Maternal education & 13.38 & 3.48 & 53 & 13.79 & 3.84 & 81 & .645 & .520 \\
\hline Number of siblings & .87 & .79 & 53 & 1.05 & .93 & 81 & 1.212 & .228 \\
\hline
\end{tabular}

736 
739 Table 2 | Summary of binary logistic regression analyses predicting antibiotic's uptake

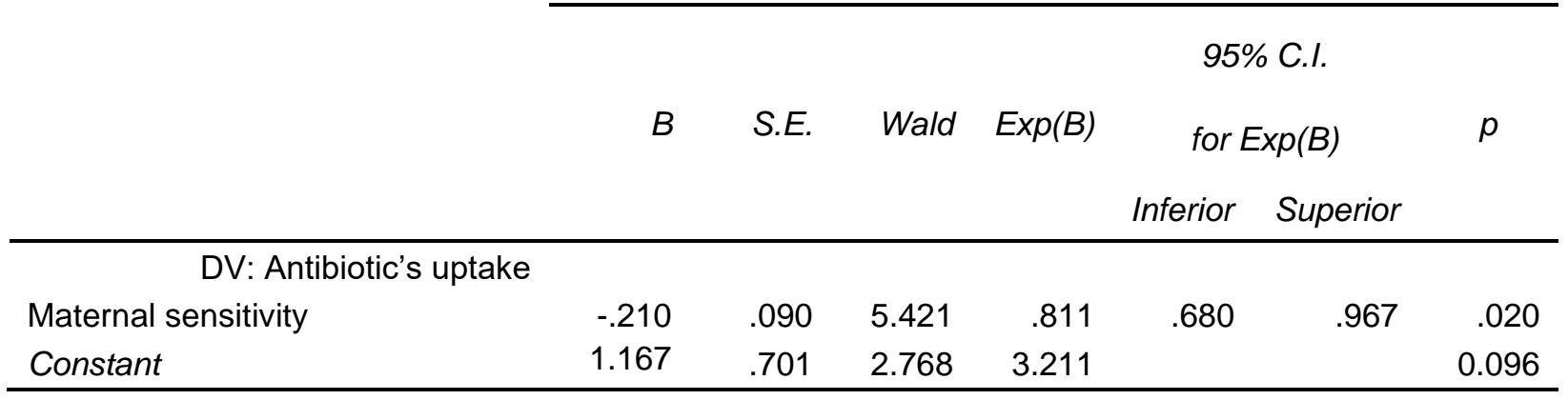

740

741

742 
743 Table 3 | Frequency of attachment patterns at 12 months according to antibiotic uptake 744 until 9 months.

\begin{tabular}{lcccc}
\hline & \multicolumn{3}{c}{ Attachment at 12-months } & \multirow{2}{*}{ Total } \\
\cline { 2 - 4 } & Avoidant (A) & Secure (B) & $\begin{array}{c}\text { Ambivalent } \\
(\mathrm{C})\end{array}$ & \\
\hline $\begin{array}{l}\text { Frequency of infants that } \\
\text { did not take antibiotics (\%) }\end{array}$ & $27(33.3 \%)^{\mathrm{a}}$ & $51(63.0 \%)^{\mathrm{a}}$ & $3(3,7 \%)^{\mathrm{b}}$ & 81 \\
Adjusted residuals & 1.1 & 4.1 & -6.2 & \\
$\begin{array}{l}\text { Frequency of infants that } \\
\text { took antibiotics (\%) }\end{array}$ & $13(24,5 \%)^{\mathrm{a}}$ & $14(26,4 \%)^{\mathrm{a}}$ & $26(49.1 \%)^{\mathrm{b}}$ & 53 \\
Adjusted residuals & -1.1 & -4.1 & 6.2 & \\
Total & 40 & 65 & 29 & 134 \\
\hline
\end{tabular}

745 Note: Pearson Chi-Square $=40.103$, DF $=2, p<.001$. Each superscript letter denotes a 746 subset of Attachment at 12-months categories whose column proportions do not differ 747 significantly from each other; $p<.05$ (column proportions test with Bonferroni adjustment). 


\section{Supplementary Figure S1:}

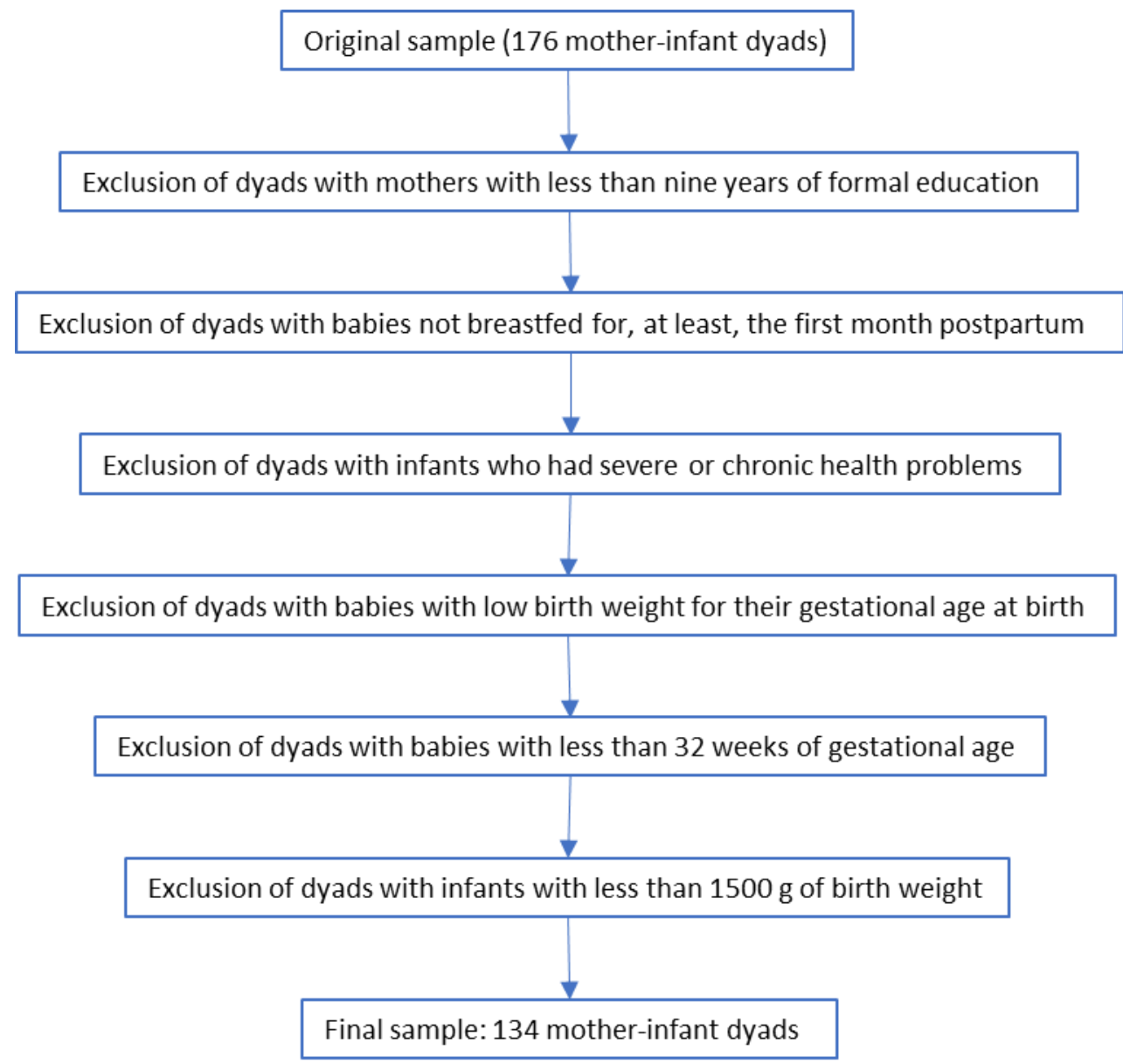

Figure S1: Flow chart of exclusion of participants. Ten dyads had more than one 751 exclusion criterion. See main text for a detailed explanation of each criterion. 
753 Supplementary Table S1| T-test for mean differences of infant and maternal factors

754 according to antibiotics consumption

\begin{tabular}{ccrrrrrrr}
\hline & \multicolumn{7}{c}{ Uptake of antibiotics } & \multicolumn{7}{c}{ uptake of antibiotics } & & \\
& $N$ & Mean & $S D$ & $N$ & Mean & \multicolumn{1}{c}{$S D$} & \multicolumn{1}{c}{$t$} & \multicolumn{1}{c}{$p$} \\
\hline Breastfeeding (in months) & 76 & 3.88 & 2.57 & 97 & 3.85 & 2.55 & .093 & .926 \\
Maternal sensitivity & 68 & 6.93 & 2.45 & 92 & 8.11 & 2.35 & 3.091 & .002 \\
Maternal control & 68 & 4.26 & 3.05 & 92 & 3.89 & 2.97 & .778 & .438 \\
Maternal unresponsivity & 68 & 2.85 & 3.09 & 92 & 2.05 & 2.33 & 1.865 & .064 \\
Infant cooperative Behavior & 68 & 6.84 & 2.62 & 92 & 8.03 & 2.30 & 3.062 & .003 \\
Infant compulsive behavior & 68 & 2.88 & 3.51 & 92 & 1.85 & 2.98 & 2.012 & .046 \\
Infant difficult behavior & 68 & 2.47 & 2.91 & 92 & 2.10 & 2.56 & .859 & .392 \\
Infant passive behavior & 68 & 1.72 & 2.57 & 92 & 2.08 & 2.03 & .976 & .331 \\
Gestational Age & 76 & 37.17 & 2.69 & 100 & 37.31 & 2.60 & .359 & .720 \\
Gestational Weight & 76 & 2750.86 & 701.48 & 99 & 2956.35 & 697.05 & 1.926 & .056 \\
Apgar 1st minute & 75 & 8.64 & 1.04 & 92 & 8.43 & 1.18 & 1.181 & .239 \\
Apgar 5th minute & 75 & 9.76 & .53 & 94 & 9.57 & .86 & 1.400 & .163 \\
Maternal age & 76 & 30.79 & 5.23 & 100 & 29.47 & 5.41 & 1.625 & .105 \\
Maternal education & 76 & 11.54 & 5.05 & 100 & 12.30 & 4.72 & 1.018 & .310 \\
Number of siblings & 76 & .88 & .80 & 100 & .99 & .94 & .803 & .423 \\
\hline
\end{tabular}

755

756 
757 Supplementary Table S2 | | Frequency of attachment patterns at 12 months according to 758 antibiotic uptake until 9 months with the original sample.

\begin{tabular}{lcccc}
\hline & \multicolumn{3}{c}{ Attachment at 12-months } & \multirow{2}{*}{ Total } \\
\cline { 2 - 4 } & Avoidant (A) & Secure (B) & $\begin{array}{c}\text { Ambivalent } \\
(\mathrm{C})\end{array}$ & \\
\hline $\begin{array}{l}\text { Frequency of infants that } \\
\text { did not take antibiotics (\%) }\end{array}$ & $34(63.0 \%)^{\mathrm{a}}$ & $61(77.2 \%)^{\mathrm{a}}$ & $5(11.6 \%)^{\mathrm{b}}$ & 100 \\
Adjusted residuals & 1.1 & 4.9 & -6.9 & \\
$\begin{array}{l}\text { Frequency of infants that } \\
\text { took antibiotics (\%) }\end{array}$ & $20(37.0 \%)^{\mathrm{a}}$ & $18(22.8 \%)^{\mathrm{a}}$ & $38(88.4 \%)^{\mathrm{b}}$ & 76 \\
Adjusted residuals & -1.1 & -4.9 & 6.9 & \\
Total & 54 & 79 & 43 & 176 \\
\hline
\end{tabular}

759 Note: Pearson Chi-Square $=50.018, \mathrm{DF}=2, p<.001$. Each superscript letter denotes a 760 subset of Attachment at 12-months categories whose column proportions do not differ 761 significantly from each other; $p<.05$ (column proportions test with Bonferroni adjustment). 